\title{
Long-term remission of hormone receptor-positive/HER2-positive metastatic breast cancer due to combined treatment with everolimus/trastuzumab/exemestane: A case report
}

\author{
JIAN WANG $^{1,2^{*}}$, CHUNXIAO SUN $^{1,2^{*}}$, XIANG HUANG $^{1}$, JINRONG QIU $^{1}$ and YONGMEI YIN ${ }^{1}$ \\ ${ }^{1}$ Department of Oncology, The First Affiliated Hospital of Nanjing Medical University; ${ }^{2}$ The First \\ Clinical College of Nanjing Medical University, Nanjing, Jiangsu 210029, P.R. China
}

Received April 28, 2016; Accepted April 6, 2017

DOI: $10.3892 / \mathrm{ol} .2017 .6311$

\begin{abstract}
The present case report describes a postmenopausal patient with hormone receptor $(\mathrm{HR})^{+} /$human epidermal growth factor receptor 2 (HER2) ${ }^{+}$metastatic breast cancer, who experienced progression of disease in bilateral lungs, lymph nodes and the liver under previous endocrine therapy and trastuzumab. Following the failure of two lines of endocrine-based treatment, the patient was administered the combined treatment of everolimus, trastuzumab and exemestane following surgical resection of the liver metastasis. A durable partial remission was achieved, which has continued for $>27$ months. This prominent clinical outcome in this patient demonstrates that the combined administration of endocrine therapy, trastuzumab and everolimus is clinically effective, and may induce long-term remission in patients with $\mathrm{HR}^{+} / \mathrm{HER} 2^{+}$metastatic breast cancer.
\end{abstract}

\section{Introduction}

Breast cancer is the most common type of cancer diagnosed in females between the ages of 30 and 59 years, and is the leading cause of cancer-associated mortality in females $<45$ years (1). Breast cancer is a heterogeneous disease with 5 molecular subtypes: Luminal A, luminal B, human epidermal growth factor receptor 2 (HER2)-enriched, normal-like breast cancer and basal-like breast cancer. Each of these subtypes exhibits important prognostic and predictive information which enables the appropriate treatment to be administered (2-4). Hormone receptor (HR) status serves a notable role in selecting systemic

Correspondence to: Dr Yongmei Yin, Department of Oncology, The First Affiliated Hospital of Nanjing Medical University, 300 Guangzhou Road, Nanjing, Jiangsu 210029, P.R. China

E-mail: ymyin@njmu.edu.cn

*Contributed equally

Key words: metastatic breast cancer, trastuzumab, endocrine therapy, everolimus hormonal therapy for patients with early and advanced breast cancer (5-7). Endocrine therapy is the preferred option for $\mathrm{HR}^{+}$ disease, even in the presence of visceral disease, unless there is an indication of endocrine resistance or rapidly progressive disease (8).

Estrogen receptor (ER) and/or progesterone receptor (PR) expression occurs in $\sim 50 \%$ of patients with HER $2^{+}$breast cancer and patients with $\mathrm{ER}^{+} / \mathrm{HER} 2^{+}$metastatic disease typically obtain less benefit from endocrine therapy, compared with patients with $\mathrm{HER} 2 / \mathrm{HR}^{+}$disease (9-14). Previous studies have suggested that cross-talk between the ER and HER2 pathways is implicated in resistance to endocrine therapy and supports tumor progression (15-18). Furthermore, several clinical studies indicate that simultaneous inhibition of the HER2 and ER signaling pathways is more effective than ER inhibition alone (19-21). These studies suggest that a combination of endocrine therapy and HER 2 inhibition may be the optimal treatment for $\mathrm{HR}^{+} / \mathrm{HER} 2^{+}$breast cancer; however, this remains unclear.

The interaction between the phosphoinositide 3-kinase (PI3K)-protein kinase B-mammalian target of rapamycin (mTOR) and ER signaling pathways is an additional emerging mechanism of endocrine resistance (22-24). mTOR is a downstream target in the HER2 signaling pathway and is associated with the activity of the ER signaling pathway. A number of clinical studies have identified the value of using allosteric mTOR inhibitors in combination with anti-estrogen therapy in advanced endocrine-resistant tumors. Everolimus, an mTOR inhibitor, is effective in treating tumors which exhibit increased activity of the mTOR signaling pathway and therefore is a potential agent for the reversal of endocrine resistance $(25,26)$.

To the best of our knowledge, there have been no previous studies on the co-suppression of the ER, HER2 and mTOR signaling pathways. The present case report describes a patient with metastatic breast cancer who has received systemic treatment with a combination of an estrogen inhibitor, trastuzumab and everolimus. Progression-free survival (PFS) of the patient has currently extended to 27 months and continues at the time of writing. Thus, the inhibition of ER, HER2 and mTOR may produce an improved clinical outcome, suggesting a combination strategy for patients with $\mathrm{HR}^{+} / \mathrm{HER} 2^{+}$breast cancer. 


\section{Case report}

In March 2002, a 48-year-old female identified a mass in her right breast. The patient underwent a modified radical mastectomy with axillary lymph node dissection in the same month. Pathological examination revealed a $2 \times 2 \mathrm{~cm}$ infiltrative ductal carcinoma that was $\mathrm{ER}^{+}, \mathrm{PR}^{+}$and HER2-, with no metastases to the axillary lymph nodes at that time (pT1NOM0, using the pathological tumor-node-metastasis staging). The patient was administered adjuvant chemotherapy comprising cyclophosphamide $\left(500 \mathrm{mg} / \mathrm{m}^{2}\right)$, epriubicin $\left(100 \mathrm{mg} / \mathrm{m}^{2}\right)$ and 5 -fluouracil $\left(500 \mathrm{mg} / \mathrm{m}^{2}\right)$ every 3 weeks over 18 weeks (for 6 cycles). Subsequently, the patient received anti-estrogen therapy (tamoxifen at $20 \mathrm{mg} /$ day) for 5 years and regular medical examinations.

In March 2010, the patient identified a hard lump in a right supraclavicular lymph node. The subsequent computed tomography (CT) scan of the chest revealed multiple nodules in the lungs (Fig. 1A and B). The subsequent excision biopsy revealed metastatic adenocarcinoma, and immunohistochemistry identified it to be $\mathrm{ER}^{+}, \mathrm{PR}^{-}$and HER2 $2^{++}$-HER $2^{+++}$. Tumor sections were deparaffinized and stained with antibodies against ER, PR, HER2, using standard protocols $(27,28)$. Fluorescent in situ hybridization (FISH) determined HER2 gene amplification. Docetaxel $\left(75 \mathrm{mg} / \mathrm{m}^{2}\right.$ on day 1$)$ and capecitabine $\left(1,250 \mathrm{mg} / \mathrm{m}^{2}\right.$ twice daily on days $\left.1-14\right)$ was administered in combination with trastuzumab $(8 \mathrm{mg} / \mathrm{kg}$ loading dose, $6 \mathrm{mg} / \mathrm{kg}$ subsequently) every 3 weeks for 3 cycles until the patient developed hand-foot syndrome. The patient experienced reddening, desquamation and numbness of the palms of the hands and soles of the feet, due to the side effects of capecitabine. Subsequently, capecitabine was replaced by gemcitabine $\left(1,000 \mathrm{mg} / \mathrm{m}^{2}\right.$ on days 1 and 8$)$. The regimen was carried on for 3 cycles until August 2010, when a CT scan indicated partial remission of the pulmonary metastasis (Fig. 1C and D). Subsequently, the patient was administered anastrozole $(1 \mathrm{mg} /$ day $)$ combined with trastuzumab $(6 \mathrm{mg} / \mathrm{kg})$ every 3 weeks. The administration of trastuzumab was stopped after 1 year for financial reasons.

In May 2012, the patient identified another lump in the right supraclavicular fossa; however, a CT revealed no progression of the lesions in the lungs. Radiation therapy of 24 Gy in 12 fractions was administered to the right supraclavicular lymph nodes with a complete response. Subsequently, the patient received endocrine therapy with fulvestrant $(250 \mathrm{mg}$ every 4 weeks) followed by stable disease for 19 months. In December 2013, a CT scan identified novel nodules in the lungs (Fig. 2) and a single $4 \times 4 \mathrm{~cm}$ low-intensity lesion in the liver (Fig. 3). In addition, the level of the tumor marker CA153 was revealed to be $>300 \mathrm{U} / 1$. The pulmonary metastases were stable. The patient underwent surgical resection of the liver metastasis 1 week later and whole-exome sequencing was performed on a partially resected specimen of the liver. Postoperative pathology revealed liver adenocarcinoma derived from the breast; immunohistochemistry indicated that they were $\mathrm{ER}^{+}$, $\mathrm{PR}^{-}$and HER2 ${ }^{+++}$(Fig. 4). The patient was administered everolimus ( $5 \mathrm{mg} /$ day) and exemestane $(25 \mathrm{mg} /$ day) in combination with trastuzumab every 3 weeks. After 5 months of treatment, there was partial remission of the lesions in the lungs and liver (Figs. 2B and 3B) with a marked decrease in levels of CA153. The patient currently remains on the combined regimen of everolimus, trastuzumab and exemestane, and regular medical examinations have identified no recurrence or additional metastases for $>27$ months (Figs. $2 \mathrm{C}$ and $3 \mathrm{C}$ ).

All procedures performed in the present case report were in accordance with The Declaration of Helsinki (1964) and its later amendments or comparable ethical standards. Written informed consent was obtained from the patient for inclusion in the present case report.

\section{Discussion}

Endocrine therapy is the fundamental treatment for patients with $\mathrm{HR}^{+}$advanced breast cancer; however, a number of patients develop resistance despite experiencing an initial benefit $(29,30)$. In the present case report, the regimens were administered on the basis of the recommendations of the National Comprehensive Cancer Network (31). For patients who are sensitive to endocrine medications, the three-sequential lines of endocrine-based therapy may be continued until accompanied symptomatic visceral diseases occur (31). Previous clinical studies have suggested that aromatase inhibitors (resulting in estrogen deprivation) may be more effective compared with tamoxifen in patients with $\mathrm{ER}^{+}$tumors that overexpress HER2 $(32,33)$. A previous clinical study demonstrated that first-line fulvestrant is at least as effective as anastrozole in exhibiting a clinical benefit response and objective response rate, and is associated with a markedly longer time to progression. Thus, first-line fulvestrant may offer longer-lasting disease control in the treatment of advanced breast cancer (34).

Cross-talk between the ER and HER2 signaling pathways is implicated in resistance to endocrine therapy and therefore supports tumor progression $(15,16)$. Massarweh et al (29) identified that tamoxifen resistance is mediated by the activation of HER family signaling which may be a result of increased expression of HER ligands and the release of membrane-bound HER ligands which act in an autocrine manner; however, this may be inhibited by the HER inhibitor gefitinib. In addition, Evans et al (35) demonstrated that AEE788, an epithelial growth factor receptor/HER2 inhibitor, increased ER-mediated transcription in $\mathrm{HER} 2^{+} / \mathrm{ER}^{+}$breast cancer cells. This indicated that letrozole in combination with AEE78 may be superior to letrozole alone for the treatment of acquired $\mathrm{ER}^{+} / \mathrm{HER}^{+}{ }^{+}$endocrine-resistant breast cancer. A previous study provided a rationale for the dual inhibition of ER and HER2; for instance, the Trastuzumab and Anastrozole Directed Against ER-Positive HER2-Positive Mammary Carcinoma study, the first randomized Phase III study to combine a hormonal agent with trastuzumab without chemotherapy to treat $\mathrm{HR}^{+} / \mathrm{HER} 2^{+}$metastatic breast cancer, has identified that the combination of trastuzumab and anastrozole improves outcomes, compared with anastrozole alone (19). An additional study has demonstrated that the combination of letrozole and trastuzumab produces durable responses in $\mathrm{HER} 2^{+}$and $\mathrm{ER}^{+}$advanced breast cancers: The median time to progression was 5.8 months and the duration of response was $>20.6$ months (9). These observations suggest that the optimal treatment for $\mathrm{HR}^{+} / \mathrm{HER} 2^{+}$breast cancers may be a combination of endocrine therapy and HER2 inhibitors (36). On the basis of the results of previous studies $(9,19,35)$, endocrine therapy 

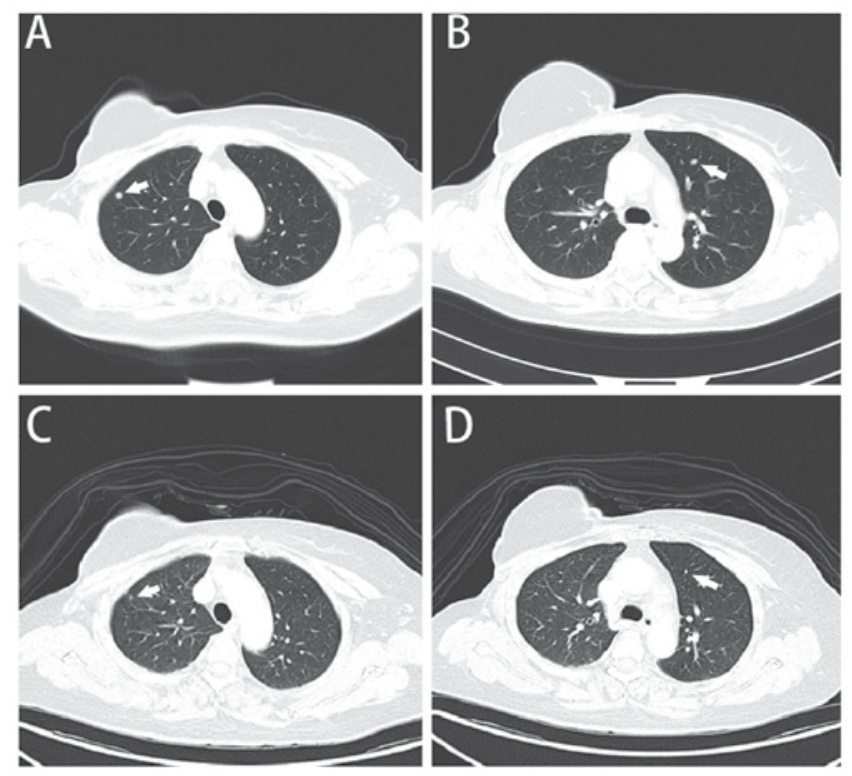

Figure 1. CT scan demonstrating lung metastasis. (A) CT scan of the chest demonstrating pulmonary metastases (March 2010). A metastatic lesion in the right lung (lesion 1) is indicated by an arrow. (B) CT scan of the chest demonstrating pulmonary metastases (March 2010). A metastatic lesion in the left lung (lesion 2) is indicated by an arrow. (C) CT scan of the chest demonstrating partial remission of lesion 1 (October 2010). (D) CT scan of the chest demonstrating the partial remission of lesion 2 (October 2010). CT, computed tomography.
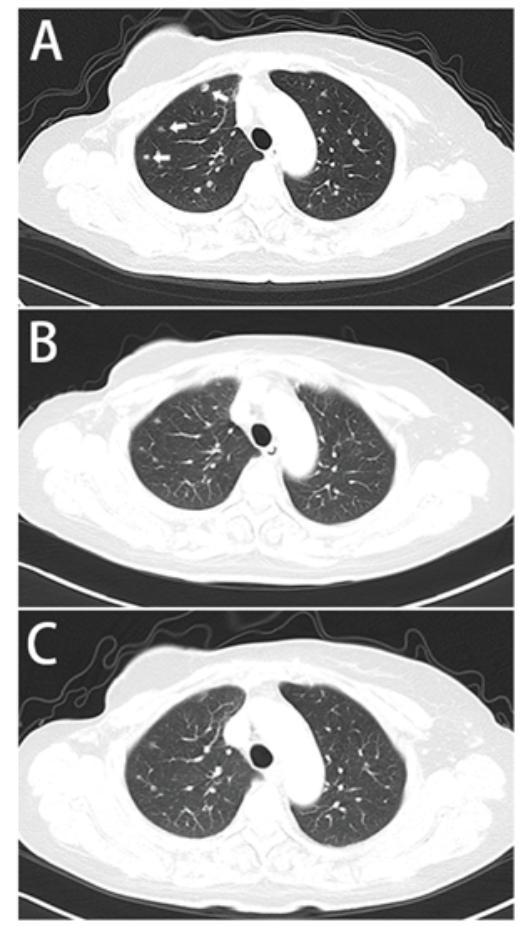

Figure 2. CT scan demonstrating the progression of the pulmonary metastases. (A) CT scan of the chest (December 2013) revealing increased number of nodules in the lungs, indicated by arrows. (B) CT scan (May 2014) revealing partial remission of the lesions in the lungs. (C) CT scan (December 2015) demonstrating stable disease. CT, computed tomography.

combined with trastuzumab in the first- and second-line treatment of advanced breast cancer was selected in the present
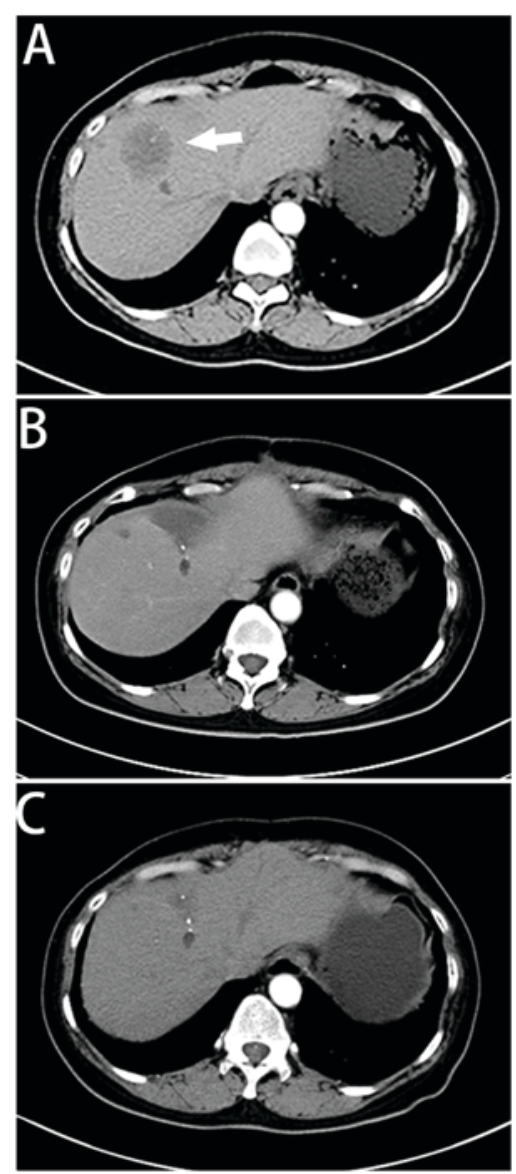

Figure 3. CT scan demonstrating liver metastasis. (A) CT scan (December 2013) of the abdomen revealing a single $4 \times 4-\mathrm{cm}$ low-density shadow in the right lobe. (B) CT scan (May 2014) of the abdomen demonstrating complete remission of the hepatic metastasis. (C) CT scan (December 2015) of the abdomen indicating no recurrence of the liver metastasis. CT, computed tomography.

case report. When the first progression was assessed in a right supraclavicular lymph node and the lungs, trastuzumab in combination with chemotherapy was recommended to control the disease. Subsequently, trastuzumab was combined with anastrozole for maintenance therapy. When the second progression was observed, following a complete response to radiation therapy, anastrozole was replaced by fulvestrant to stabilize the disease for a longer period of time. However, the combination of trastuzumab and endocrine therapy may only be recommended for patients with less extensive or asymptomatic metastatic disease. For young patients, or those with life-threatening or symptomatic disease, chemotherapy-based HER2-targeted combination therapy may be preferred.

In the present report, after 19 months of PFS, a single liver metastasis was identified by $\mathrm{CT}$. Although liver resection in patients with breast cancer exhibiting extrahepatic metastases has been debated, a number of studies determining the role of therapeutic hepatic metastasectomy have demonstrated encouraging survival statistics for patients with tumors of low histological grade, long disease-free interval and patients with well-controlled extrahepatic metastases (37-39). Chua et al (40) identified a median survival time following partial hepatectomy of 40 months and a 5-year survival rate of $40 \%$, which suggested that surgery for liver metastases, 


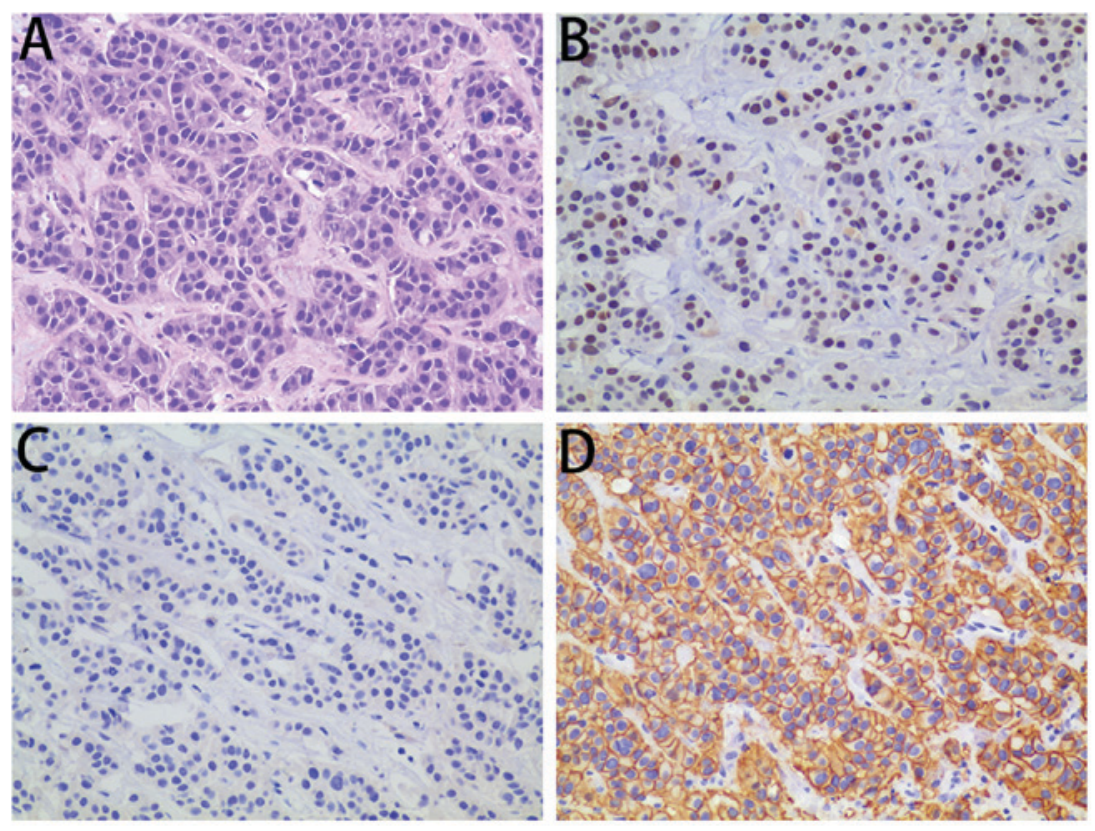

Figure 4. Pathological results of liver metastasis using the labeled streptavidin-binding technique. (A) Metastatic adenocarcinoma, consistent with origin from the breast. (B) ER ${ }^{+}$cells (25\%). (C) PR' cells (0\%). (D) HER2 $2^{+}$cells (score 3+). Magnification, x200.

due to breast cancer, may be an effective therapeutic strategy. However, a number of studies have demonstrated that hormone-refractory liver metastasis is a negative predictor of overall survival rate $(38,41)$. Therefore, continued treatment following the resection of liver metastases is of importance.

The question remains whether, following long PFS owing to dual inhibition of ER and HER, there is a way of improving the regimen for patients confronted with progression. An emerging mechanism of endocrine resistance is the interaction between the PI3K-protein kinase B-mTOR and ER signaling pathways (22-24). In a previous study involving patients with newly diagnosed breast cancer, neoadjuvant everolimus combined with letrozole improved the clinical response rate and decreased tumor cell viability, compared with letrozole alone (42). The Tamoxifen Plus Everolimus randomized Groupe d'Investigateurs Nationaux pour l'Etude des Cancers de l'Ovaire et du Sein trial (43) identified an improved time to progression: 4.5 months with tamoxifen alone vs. 8.6 months with tamoxifen plus everolimus. The Breast Cancer Trials of Oral Everolimus-2 (BOLERO-2) study (44) revealed that the addition of everolimus to exemestane markedly improved PFS; the median PFS time, on the basis of central assessment, was 10.6 and 4.1 months, respectively (hazard ratio, 0.36 ; 95\% confidence interval, 0.27-0.47; $\mathrm{P}<0.001)$. Notably, everolimus was additionally identified to reverse trastuzumab in metastatic breast cancer. The results of the BOLERO-3 study (26) demonstrated that the addition of everolimus to trastuzumab with vinorelbine markedly prolonged PFS time in patients with trastuzumab-resistant and taxane-pretreated HER $2^{+}$advanced breast cancer; however, their hormone receptor status was not assessed. Patients with ER breast cancer exhibit an increased benefit compared with patients with $\mathrm{ER}^{+}$breast cancer, indicating the importance of dual inhibition of the HER2 signal and the ER signaling pathway. Patients with a loss of phosphatase and tensin homolog (PTEN) and mutations to phosphatidylinositol 4,5-bisphosphate 3-kinase catalytic subunit- $\alpha$ isoform (PIK3CA) have a greater sensitivity to everolimus; although next-generation sequencing of the resected liver specimen revealed no loss of PTEN and or PIK3CA mutations, it remains likely that the patient would benefit from everolimus $(45,46)$.

The patient was recommended to continue to follow the principle of dual inhibition of ER and HER2. Everolimus was introduced into the regimen on the assumption that it may strengthen the therapeutic effect. Although there was no clinical evidence of the efficacy of exemestane with everolimus and trastuzumab, the patient provided written informed consent for the treatment. The patient's response was continually monitored during treatment. The patient achieved a long-term remission and is in good health at the time of writing.

The combined regimen of exemestane with everolimus and trastuzumab may be used for similar cases. To the best of our knowledge, the present case report is the first in which the patient's PFS reached $>27$ months. Additional observation has been undertaken and case series or small-scale clinical trials would be welcome to increase understanding on this topic.

\section{References}

1. Chen W, Zheng R, Baade PD, Zhang S, Zeng H, Bray F, Jemal A, Yu XQ and He J: Cancer statistics in China, 2015. CA Cancer J Clin 66: 115-132, 2016

2. Sorlie T, Perou CM, Tibshirani R, Aas T, Geisler S, Johnsen H, Hastie T, Eisen MB, van de Rijn M, Jeffrey SS, et al: Gene expression patterns of breast carcinomas distinguish tumor subclasses with clinical implications. Proc Natl Acad Sci USA 98: 10869-10874, 2001.

3. Parker JS, Mullins M, Cheang MC, Leung S, Voduc D, Vickery T, Davies S, Fauron C, He X, Hu Z, et al: Supervised risk predictor of breast cancer based on intrinsic subtypes. J Clin Oncol 27: 1160-1167, 2009. 
4. Perou CM, Sørlie T, Eisen MB, van de Rijn M, Jeffrey SS, Rees CA, Pollack JR, Ross DT, Johnsen H, Akslen LA, et al: Molecular portraits of human breast tumours. Nature 406: 747-752, 2000

5. Goldhirsch A, Coates AS, Gelber RD, Glick JH, Thürlimann B and Senn HJ; St Gallen Expert Panel Members: First-select the target: Better choice of adjuvant treatments for breast cancer patients. Ann Oncol 17: 1772-1776, 2006.

6. Buzdar AU: Endocrine therapy in the treatment of metastatic breast cancer. Semin Oncol 28: 291-304, 2001.

7. Jordan C: Historical perspective on hormonal therapy of advanced breast cancer. Clin Ther 24 (Suppl A): A3-A16, 2002.

8. Cardoso F, Costa A, Norton L, Cameron D, Cufer T, Fallowfield L, Francis P, Gligorov J, Kyriakides S, Lin N, et al: 1st International consensus guidelines for advanced breast cancer (ABC 1). Breast 21: 242-252, 2012

9. Marcom PK, Isaacs C, Harris L, Wong ZW, Kommarreddy A, Novielli N, Mann G, Tao Y and Ellis MJ: The combination of letrozole and trastuzumab as first or second-line biological therapy produces durable responses in a subset of HER2 positive and ER positive advanced breast cancers. Breast Cancer Res Treat 102: 43-49, 2007.

10. Ellis M: Overcoming endocrine therapy resistance by signal transduction inhibition. Oncologist 9 (Suppl 3): S20-S26, 2004.

11. Dowsett M, Allred C, Knox J, Quinn E, Salter J, Wale C, Cuzick J, Houghton J, Williams N, Mallon E, et al: Relationship between quantitative estrogen and progesterone receptor expression and human epidermal growth factor receptor 2 (HER-2) status with recurrence in the Arimidex, Tamoxifen, Alone or in Combination trial. J Clin Oncol 26: 1059-1065, 2008.

12. Jones A: Combining trastuzumab (Herceptin) with hormonal therapy in breast cancer: What can be expected and why? Ann Oncol 14: 1697-1704, 2003

13. Lipton A, Ali SM, Leitzel K, Demers L, Chinchilli V, Engle L, Harvey HA, Brady C, Nalin CM, Dugan M, et al: Elevated serum Her-2/neu level predicts decreased response to hormone therapy in metastatic breast cancer. J Clin Oncol 20: 1467-1472, 2002.

14. De Laurentiis M, Arpino G, Massarelli E, Ruggiero A, Carlomagno C, Ciardiello F, Tortora G, D'Agostino D, Caputo F, Cancello G, et al: A meta-analysis on the interaction between HER-2 expression and response to endocrine treatment in advanced breast cancer. Clin Cancer Res 11:4741-4748, 2005

15. Chen Z, Wang Y, Warden C and Chen S: Cross-talk between ER and HER2 regulates c-MYC-mediated glutamine metabolism in aromatase inhibitor resistant breast cancer cells. J Steroid Biochem Mol Biol 149: 118-127, 2015.

16. Cui J, Germer K, Wu T, Wang J, Luo J, Wang SC, Wang Q and Zhang X: Cross-talk between HER2 and MED1 regulates tamoxifen resistance of human breast cancer cells. Cancer Res 72: 5625-5634, 2012.

17. Shou J, Massarweh S, Osborne CK, Wakeling AE, Ali S, Weiss H and Schiff R: Mechanisms of tamoxifen resistance: Increased estrogen receptor-HER2/neu cross-talk in ER/HER2-positive breast cancer. J Natl Cancer Inst 96: 926-935, 2004.

18. Osborne CK, Shou J, Massarweh S and Schiff R: Crosstalk between estrogen receptor and growth factor receptor pathways as a cause for endocrine therapy resistance in breast cancer. Clin Cancer Res 11: 865s-870s, 2005

19. Kaufman B, Mackey JR, Clemens MR, Bapsy PP, Vaid A, Wardley A, Tjulandin S, Jahn M, Lehle M, Feyereislova A, et al: Trastuzumab plus anastrozole versus anastrozole alone for the treatment of postmenopausal women with human epidermal growth factor receptor 2-positive, hormone receptor-positive metastatic breast cancer: Results from the randomized phase III TAnDEM study. J Clin Oncol 27: 5529-5537, 2009.

20. Huober J, Fasching PA, Barsoum M, Petruzelka L, Wallwiener D, Thomssen C, Reimer T, Paepke S, Azim HA, Ragosch V, et al: Higher efficacy of letrozole in combination with trastuzumab compared to letrozole monotherapy as first-line treatment in patients with HER2-positive, hormone-receptor-positive metastatic breast cancer-results of the eLEcTRA trial. Breast 21 27-33, 2012.

21. Johnston S, Pippen J Jr, Pivot X, Lichinitser M, Sadeghi S, Dieras V, Gomez HL, Romieu G, Manikhas A, Kennedy MJ, et al: Lapatinib combined with letrozole versus letrozole and placebo as first-line therapy for postmenopausal hormone receptor-positive metastatic breast cancer. J Clin Oncol 27: 5538-5546, 2009.
22. Johnston SR: Clinical efforts to combine endocrine agents with targeted therapies against epidermal growth factor receptor/human epidermal growth factor receptor 2 and mammalian target of rapamycin in breast cancer. Clin Cancer Res 12: 1061s-1068s, 2006.

23. Bostner J, Karlsson E, Pandiyan MJ, Westman H, Skoog L, Fornander T, Nordenskjöld B and Stål O: Activation of Akt, mTOR, and the estrogen receptor as a signature to predict tamoxifen treatment benefit. Breast Cancer Res Treat 137: 397-406, 2013

24. Grunt TW and Mariani GL: Novel approaches for molecular targeted therapy of breast cancer: Interfering with PI3K/AKT/mTORsignaling.CurrCancerDrugTargets 13:188-204, 2013.

25. Hurvitz SA, Andre F, Jiang Z, Shao Z, Mano MS, Neciosup SP, Tseng LM, Zhang Q, Shen K, Liu D, et al: Combination of everolimus with trastuzumab plus paclitaxel as first-line treatment for patients with HER2-positive advanced breast cancer (BOLERO-1): A phase 3, randomised, double-blind, multicentre trial. Lancet Oncol 16: 816-829, 2015.

26. André F, O'Regan R, Ozguroglu M, Toi M, Xu B, Jerusalem G, Masuda N, Wilks S, Arena F, Isaacs C, et al: Everolimus for women with trastuzumab-resistant, HER2-positive, advanced breast cancer (BOLERO-3): A randomised, double-blind, placebo-controlled phase 3 trial. Lancet Oncol 15: 580-591, 2014.

27. Hammond ME, Hayes DF, Dowestt M, Allred DC, Hagerty KL, Badve S, Fitzgibbons PL, Francis G, Goldstein NS, Hayes M, et al: American Society of Clinical Oncology/College of American Pathologists guideline recommendations for immunohistochemical testing of estrogen and progesterone receptors in breast cancer (unabridged version). Arch Pathol Lab Med 134: e48-e72, 2010.

28. Wolff AC, Hammond EA, Hicks DG, Dowsett M, McShane LM, Allison KH, Allred DC, Bartlett JM, Bilous M, Fitzgibbons $\mathrm{P}$, et al: Recommendations for human epidermal growth factor receptor 2 testing in breast cancer: American Society of Clinical Oncology/College of American Pathologists clinical practice guideline update. J Clin Oncol 31: 3997-4013, 2013.

29. Massarweh S, Osborne CK, Creighton CJ, Qin L, Tsimelzon A, Huang S, Weiss H, Rimawi M and Schiff R: Tamoxifen resistance in breast tumors is driven by growth factor receptor signaling with repression of classic estrogen receptor genomic function. Cancer Res 68: 826-833, 2008.

30. Donders F, Kuypers D, Wolter P and Neven P: Everolimus in acute kidney injury in a patient with breast cancer: A case report. J Med Case Rep 8: 386, 2014

31. National Comprehensive Cancer Network. NCCN Clinical Practice Guidelines in Oncology: Breast Cancer, V.3.2015. http://www.nccn.org/professionals/physician_gls/pdf/breast.pdf. Accessed August 30, 2015.

32. Dowsett M, Cuzick J, Wale C, Howell T, Houghton J and Baum M: Retrospective analysis of time to recurrence in the ATAC trial according to hormone receptor status: An hypothesis-generating study. J Clin Oncol 23: 7512-7517, 2005.

33. Ellis MJ, Coop A, Singh B, Mauriac L, Llombert-Cussac A, Jänicke F, Miller WR, Evans DB, Dugan M, Brady C, et al: Letrozole is more effective neoadjuvant endocrine therapy than tamoxifen for ErbB-1- and/or ErbB-2-positive, estrogen receptor-positive primary breast cancer: Evidence from a phase III randomized trial. J Clin Oncol 19: 3808-3816, 2001.

34. Robertson JF, Llombart-Cussac A, Rolski J, Feltl D, Dewar J, Macpherson E, Lindemann J and Ellis MJ: Activity of fulvestrant $500 \mathrm{mg}$ versus anastrozole $1 \mathrm{mg}$ as first-line treatment for advanced breast cancer: Results from the FIRST study. J Clin Oncol 27: 4530-4535, 2009.

35. Evans AH, Pancholi S, Farmer I, Thornhill A, Evans DB, Johnston SR, Dowsett $M$ and Martin LA: EGFR/HER2 inhibitor AEE788 increases ER-mediated transcription in HER2/ER-positive breast cancer cells but functions synergistically with endocrine therapy. Br J Cancer 102: 1235-1243, 2010.

36. Glück S, Arteaga CL and Osborne CK: Optimizing chemotherapy-free survival for the ER/HER2-positive metastatic breast cancer patient. Clin Cancer Res 17: 5559-5561, 2011.

37. Abbott DE, Brouquet A, Mittendorf EA, Andreou A, Meric-Bernstam F, Valero V, Green MC, Kuerer HM, Curley SA, Abdalla EK, et al: Resection of liver metastases from breast cancer: Estrogen receptor status and response to chemotherapy before metastasectomy define outcome. Surgery 151: 710-716, 2012. 
38. Hoffmann K, Franz C, Hinz U, Schirmacher P, Herfarth C, Eichbaum M, Büchler MW and Schemmer P: Liver resection for multimodal treatment of breast cancer metastases: Identification of prognostic factors. Ann Surg Oncol 17: 1546-1554, 2010.

39. Singletary SE, Walsh G, Vauthey JN, Curley S, Sawaya R, Weber KL, Meric F and Hortobágyi GN: A role for curative surgery in the treatment of selected patients with metastatic breast cancer. Oncologist 8: 241-251, 2003.

40. Chua TC, Saxena A, Liauw W, Chu F and Morris DL: Hepatic resection for metastatic breast cancer: A systematic review. Eur J Cancer 47: 2282-2290, 2011.

41. Martinez SR, Young SE, Giuliano AE and Bilchik AJ: The utility of estrogen receptor, progesterone receptor, and Her-2/neu status to predict survival in patients undergoing hepatic resection for breast cancer metastases. Am J Surg 191: 281-283, 2006.

42. Baselga J, Semiglazov V, van Dam P, Manikhas A, Bellet M, Mayordomo J, Campone M, Kubista E, Greil R, Bianchi G, et al: Phase II randomized study of neoadjuvant everolimus plus letrozole compared with placebo plus letrozole in patients with estrogen receptor-positive breast cancer. J Clin Oncol 27 2630-2637, 2009.
43. Bachelot T, Bourgier C, Cropet C, Ray-Coquard I, Ferrero JM, Freyer G, Abadie-Lacourtoisie S, Eymard JC, Debled M, Spaëth D, et al: Randomized phase II trial of everolimus in combination with tamoxifen in patients with hormone receptor-positive, human epidermal growth factor receptor 2-negative metastatic breast cancer with prior exposure to aromatase inhibitors: A GINECO study. J Clin Oncol 30: 2718-2724, 2012.

44. Baselga J, Campone M, Piccart M, Burris HA III, Rugo HS Sahmoud T, Noguchi S, Gnant M, Pritchard KI, Lebrun F, et al: Everolimus in postmenopausal hormone-receptor-positive advanced breast cancer. N Engl J Med 366: 520-529, 2012.

45. Gonzalez-Angulo AM and Blumenschein GR Jr: Defining biomarkers to predict sensitivity to $\mathrm{PI} 3 \mathrm{~K} / \mathrm{Akt} / \mathrm{mTOR}$ pathway inhibitors in breast cancer. Cancer Treat Rev 39: 313-320, 2013.

46. Hurvitz SA, Kalous O, Conklin D, Desai AJ, Dering J, Anderson L, O'Brien NA, Kolarova T, Finn RS, Linnartz R, et al: In vitro activity of the mTOR inhibitor everolimus, in a large panel of breast cancer cell lines and analysis for predictors of response. Breast Cancer Res Treat 149: 669-680, 2015. 